\title{
An Assessment of Sleep Duration and Determinants of Health in a Cross- Sectional Sample of Gynecologic Cancer Survivors in Los Angeles County
}

\author{
Ma'at Hembrick, Makala E. Conner, \& Heather P. Tarleton \\ Department of Health \& Human Sciences, Loyola Marymount University, Los Angeles, CA \\ bttps:/ / doi.org/10.33697/ ajur.2020.017 \\ Students:mbembrick.21@gmail.com,mecmakala@gmail.com \\ Mentor: heather.tarleton@lmu.edu*
}

\begin{abstract}
Cancer survivors have an increased risk of treatment-related deficits in physical health and low health-related quality of life. In this cross-sectional study, a health questionnaire was mailed to women from the Los Angeles County Cancer Surveillance Program aged 45-70 and diagnosed with cervical, endometrial, or ovarian cancer in 2005-2014. Of the 5,941 surveys with valid postal addresses, $586(10 \%)$ were completed and returned. The average age of respondents was 66 years old, and $36 \%$ identified as nonwhite. Non-white respondents were less likely to have a college degree $(p<0.001)$, more likely to sleep for less than seven hours each night $(p<0.001)$, experience bodily pain $(p<0.001)$, and have a diagnosis of cervical cancer $(p=0.002)$, when compared to white respondents. Health behaviors and determinants were examined across cervical, endometrial, and ovarian cancer cases. Cervical cancer survivors reported sleeping less than 7 hours per night, on average $(p=0.015)$. Race was associated with sleep duration among endometrial $(p=0.002)$ and ovarian $(p=0.003)$ cancer survivors. Menopausal status was associated with the relationship between race and sleep duration $(p<0.001)$. Depression was inversely related to sleep duration $(p=0.022)$ but was not associated with race, menopausal status, time since treatment, physical activity, or cancer type. Postmenopausal cervical cancer survivors reported a moderate concern about fall risk compared to their premenopausal counterparts $(p=0.048)$. Physical activity levels increased as time since treatment increased $(p=0.003)$ regardless of cancer type. Race, menopausal status, depression, and cancer type impacted the sleep duration.
\end{abstract}

\section{KEYWORDS}

Health Disparities; Sleep Duration; Depression; Gynecologic Cancers; Survivorship Care

\section{INTRODUCTION}

Cancer patients live more prolonged post-treatment than previous generations, as a result of technological advances that have increased early detection of cancer and improved the effectiveness of treatment plans. ${ }^{1-3}$ Cancer survivors face a range of adjustments to their quality of life following cancer diagnosis and treatment, including possible unemployment, limitations in their daily living activities, and fear of cancer recurrence. ${ }^{4}$ Previously published studies have shown that quality of life decreases in the time after treatment. ${ }^{4,5}$ Lingering post-treatment symptoms have not been thoroughly investigated across cancer types or among diverse populations. Given the projected growth in cancer patients' numbers and racial diversity, increased attention must be paid to cancer survivors' quality of life. ${ }^{2}$ This study analyzes three interconnected determinants of health-related quality of life (H.R.Q.O.L.) - physical activity, depression, and sleep duration - to highlight possible gaps in cancer survivorship care that need attention.

\section{Physical Activity}

Previous studies have analyzed the delivery format and the benefits of physical activity for cancer survivors. For example, homebased intervention for gynecologic cancer survivors that combined weekly exercise prescriptions coupled with either in-person or telephone counseling was highly successful compared to single format interventions. ${ }^{6}$ The beneficial impact of the combined format extended to both the psychological and physical domains of health. A second study that focused on a combined format by Yun et al. noted that an exercise intervention program implemented with health education, leadership, and coaching on physical activity and dietary habits, and distress management led to improved quality of life. The intervention group in the Yun et al. study reported a decrease in anxiety and distress compared to the control group and an increase in the confidence to make health behavior changes. ${ }^{7}$ Additional studies of exercise interventions with cancer survivors have reported reductions in perceived aches and pains and improved performance on fitness tests. ${ }^{8,9}$ 
Despite the practical benefits of physical activity, barriers to participation exist across socioeconomic status (S.E.S.), and race and many survivors exhibit a low motivation to participate. The most frequently reported barriers among all cancer survivors included competing time commitments between work and personal recreation and treatment-related limitations such as physical discomfort or fatigue. ${ }^{10-13}$ Cost of gym memberships or exercise class participation was a reported barrier for survivors from lower S.E.S. backgrounds but was not concretely associated with race alone. ${ }^{14}$ Family caregiving demands, transportation to exercise facilities and neighborhood availability of exercise spaces, health literacy, and patient-provider communication regarding survivorship care plans are mentioned more frequently among subgroups of non-white and lower S.E.S. cancer survivors. ${ }^{14-16}$

A few targeted interventions have been developed to begin to address these health disparities. A tailored exercise program was designed by Stewart et al. for African-American women to intervene on disproportionate endometrial survivorship among racial minorities. ${ }^{17}$ The intervention acknowledged a disparity in comorbidities and possible socioeconomic barriers by combining the exercise program with educational workshops on improving nutritional status at various income levels. A similar approach was implemented by Ross et al. on the relationship between lack of physical activity and socioeconomic status with endometrial cancer survivorship..$^{18}$ The study found physical activity to be lower among African-American women who lived in low S.E.S. areas. This subgroup also had significantly higher rates of obesity-related comorbidities, such as hypertension, diabetes, hyperlipidemia, and metabolic syndrome, in comparison to women from higher S.E.S. areas. ${ }^{18}$

In the absence of racial and socioeconomic disparities, cancer survivors of all demographic backgrounds are susceptible to low motivation to participate in social activities and health-promoting behaviors. Reported sentiments include feeling "too tired and "not well enough" or a complete "lack of interest" if they did not engage in exercise before the cancer diagnosis. ${ }^{19}$ Feeling tired, experiencing pain, and being inactive also increase the likelihood of falls after cancer treatment, leading to fractures and disability. 20-22 Survivors can be hesitant to change their lifestyles if they do not view inactivity or fatigue as a threat to cancer survivorship and quality of life. ${ }^{12,23}$ This underscores the Health Beliefs Model's importance and provides cues to action tailored to cancer survivors.

\section{Depression and Sleep Disturbances}

Depression is prevalent among gynecologic cancer survivors and is commonly associated with a lack of social support, perceived quality of life, feelings of loneliness and isolation, and cancer-specific stress and fear of recurrence. ${ }^{24,25}$ The depressive symptoms that many cancer survivors exhibit may not reach the clinical diagnosis level, yet they still concern in regards to successful survivorship. ${ }^{26}$ The pervasiveness of symptoms was examined in a study that focused on the quality of life among cervical cancer survivors. Nearly $63 \%$ of the sample size suffered from depression, while $50 \%$ suffered from anxiety. ${ }^{27}$ This prevalence is concerning given the projected increase in the number of cancer survivors. Furthermore, reported symptoms could linger for up to ten years after treatment, and often include: feelings of isolation, irritability, fear of cancer recurrence, post-traumatic stress syndrome, and feelings of hopelessness. ${ }^{26}$ Higher risk of depression is associated with lower socioeconomic status, lower employment levels, and fewer financial resources. ${ }^{28}$

Gynecologic cancer survivors experience a higher prevalence of fatigue and sleep disturbance, or insomnia, as compared to cancer-free adults. ${ }^{28}$ The group of women studied by Westin et al. presented as either being unable to fall asleep or stay asleep during the night, with the issue being most pronounced for cervical cancer survivors. Depressive symptoms are commonly associated with sleep disturbances, which can, in turn, cyclically exacerbate depressive symptoms. ${ }^{29}$ Given that fatigue and sleep disturbances are typical post-treatment experiences, the expectation of their occurrence often leads to an under-diagnosis of depression and anxiety among survivors. ${ }^{28,29}$

Higher rates of insomnia, accompanied by depressive symptoms, may reduce cancer survivors' overall quality of life. ${ }^{26}$ One proposed solution is healthcare provider screening for these indicators of poor H.R.Q.O.L. earlier in the survivorship continuum. However, a study by Zhou et al. found that when survivors disclosed their battle with insomnia, healthcare providers did not have the training to provide an effective intervention or treatment plan. ${ }^{30}$

This study is designed to expand current knowledge of physical activity, fall risk, sleep disturbance, and depression as determinants of HRQOL among gynecologic cancer survivors. Analyzing these determinants with the inclusion of racial group identification, menopausal status, cancer type, and treatment characteristics should provide a clearer understanding of the potential interconnectedness among the determinants and across patient subgroups. This expanded knowledge base may help healthcare providers understand the scale and importance of identifying H.R.Q.O.L. deficits among cancer survivors and could inform the development of efficacious and meaningful interventions. 


\section{METHODS}

\section{Study Population and Data Collection}

The study was approved by the Loyola Marymount University Institutional Review Board (LMU IRB 2014 S.P. 27 and LMU IRB 2015 S.P. 23) and the California Health and Human Services Agency Institutional Review Board (Protocol ID 14-02-1507) per the Helsinki Declaration of 1975, as revised in 1983, and the Declaration of the World Medical Association.

Gynecologic cancer survivors were identified using the Los Angeles Cancer Surveillance Program. An anonymous questionnaire was sent by mail to 6,516 gynecologic cancer survivors with addresses in Los Angeles County aged 45-70 and diagnosed with cervical, endometrial, or ovarian cancer between 2005-2014. A self-addressed and stamped return envelope was included with each mailed questionnaire so that recipients would not feel compelled to provide their personal information as the sender of the envelope and reduce potential financial barriers associated with purchasing an envelope or postage. Approximately $9 \%$ of the 6,516 questionnaires $(n=575)$ were returned due to an incorrect address. Of the remaining 5,941 mailed questionnaires, 586 questionnaires $(10 \%)$ were completed and returned.

Demographic variables included education, race, menopausal status, cancer type, treatment type, and time since the last treatment. Most questions had a closed structure to collect information about demographic characteristics, medical history, health behaviors, and H.R.Q.O.L. (please reference the Appendix). For education, race, menopausal status, and treatment type, respondents chose from predetermined options. Since the last treatment, cancer type and time were collected by respondents individually writing in the primary type of cancer they were diagnosed with and the month and year of their last treatment. H.R.Q.O.L. variables included a self-reported number of falls within the past year, perceived risk of falling, activity levels, depression, and sleep duration.

\section{Data Analysis}

Continuous and categorical data collected from the questionnaires were coded using Microsoft Excel and imported into S.P.S.S. (Version 26, Armonk, NY: I.B.M. Corp). Continuous and categorical variables were collapsed according to the analysis formats depicted in Table 4.

The American College of Sports Medicine guidelines were used to classify respondents' physical activity levels based on the recommendation of $\geq 150$ minutes of physical activity per week. The sleep duration categorization was based on the recommendation that adults sleep at least 7 hours per night. ${ }^{31}$ Sleep duration was measured by respondents indicating their average rate of sleep as "4 hours or less", "5-6 hours", "7 hours or more". Health behavior and quality of life questions were worded following validated closed-formats from the SF36 and NIH PROMIS instruments. The frequency of falling was measured by the recalled number of times fallen in the past twelve months. ${ }^{32}$ Respondents evaluated their risk for falling by answering the statement, "I am at risk for falls" on a 5-point Likert scale, ranging from "strongly disagree" to "strongly agree." Respondents evaluated if they experienced "bodily pain" within the past 4-weeks by answering "none," "very little," "moderate," "quite a bit" and "severe." The same categorical scale was used by participants to evaluate depression. Participants indicated their comorbidities (past and present) from various conditions, including anemia, stroke, ulcer, hepatitis, emphysema, type 1 , and 2 diabetes. The number of comorbidities was created by summation of self-reported conditions to provide a cross-sectional prevalence of general health burden among respondents.

T-tests and ANOVA of continuous variables and Chi-squared analysis of categorical variables were performed to examine relationships across cancer type, race, menopausal status, treatment type, and time since the last treatment. Noteworthy relationships were characterized using a p-value threshold of 0.05 . In contrast, $\mathrm{p}$-values greater than 0.05 and less than or equal to 0.10 were identified as suggested relationships for future analysis in a larger sample.

\section{RESULTS}

The demographics of the 6,516 registry enrollees were: 4,504 endometrial cancer (69\%), 1,180 ovarian cancer (18\%), and 832 cervical cancer (13\%). The average age was $63 \pm 6.7$ years with the racial distribution: $73 \%$ white, $8 \%$ black, $11 \%$ Asian, and $33 \%$ of participants across all racial groups identifying as having Hispanic ethnicity. Concerning time since treatment, $14.5 \%$ of registry enrollees were treated $<1$ year from the questionnaires' mailing. Fifty-one percent (51\%) were 1-4 years from treatment, and $34.5 \%$ were five years or more from treatment.

The demographics of survey respondents are comparable to the registry enrollment demographics, except for identifying Hispanic ethnicity. This exception is likely due to the registry protocol of counting both race and ethnicity versus the consideration for this study of Hispanic as a unique category for individuals that do not identify racially as White, Black, American Indian, Asian/Asian Pacific, or Other. 
The respondents' average age is $66.54 \pm 2.6$ years, with $65-69$-year-olds making up $92 \%$ of the sample (Table 1). Approximately $36 \%$ identify as non-white, with that subgroup comprised mainly of those identifying as Hispanic (48\%), Black/African-American $(20 \%)$, and Asian/Asian-Pacific Islander (28\%). Non-white respondents are less likely to have a college degree $(p<0.001)$, more likely to sleep for less than seven hours $(p<0.001)$, report having bodily, physical pain $(p<0.001)$, and have a diagnosis of cervical cancer $(p=0.002)$.

\begin{tabular}{|c|c|c|c|c|}
\hline Characteristic & $\mathbf{N}$ & Non-white & White & $p$ \\
\hline Age & & & & 0.924 \\
\hline 49-64 yrs old & $34(5.8 \%)$ & $13(6.2 \%)$ & $21(5.6 \%)$ & \\
\hline 65-69 yrs old & $540(92.2 \%)$ & $193(91.9 \%)$ & $347(92.8 \%)$ & \\
\hline $70+$ yrs old & $10(1.7 \%)$ & $4(1.9 \%)$ & $6(1.6 \%)$ & \\
\hline Missing & $2(0.3 \%)$ & & & \\
\hline Race/Ethnicity & & & & $<0.001$ \\
\hline American Indian & $3(0.5 \%)$ & $3(1.4 \%)$ & $0(0 \%)$ & \\
\hline Asian/ Asian Pacific & $60(9.9 \%)$ & $60(28.3 \%)$ & $0(0 \%)$ & \\
\hline Black & $43(7.1 \%)$ & $43(20.3 \%)$ & $0(0 \%)$ & \\
\hline Hispanic & $101(16.7 \%)$ & $101(47.6 \%)$ & $0(0 \%)$ & \\
\hline Other & $5(0.9 \%)$ & $5(2.4 \%)$ & $0(0 \%)$ & \\
\hline White & $374(61.7 \%)$ & $0(0 \%)$ & $374(100 \%)$ & \\
\hline Education level & & & & $<0.001$ \\
\hline$\leq$ High School & $98(16.7 \%)$ & $57(26.9 \%)$ & $27(7.2 \%)$ & \\
\hline Some college & $117(20.0 \%)$ & $51(24.1 \%)$ & $81(21.7 \%)$ & \\
\hline College graduate & $369(63.0 \%)$ & $104(49.1 \%)$ & $265(71.0 \%)$ & \\
\hline Missing & $2(0.3 \%)$ & & & \\
\hline Menopausal status & & & & 0.096 \\
\hline Premenopausal & $237(40.4 \%)$ & $96(45.5 \%)$ & $141(38.4 \%)$ & \\
\hline Postmenopausal & $341(58.2 \%)$ & $115(54.5 \%)$ & $226(61.6 \%)$ & \\
\hline Missing & $8(1.4 \%)$ & & & \\
\hline Treatment Type & & & & 0.149 \\
\hline Chemotherapy & $29(4.9 . \%)$ & $16(8.1 \%)$ & $13(3.7 \%)$ & \\
\hline Radiation & $153(26.1 \%)$ & $54(27.4 \%)$ & $99(27.8 \%)$ & \\
\hline Surgery & $1(0.2 \%)$ & $0(0 \%)$ & $1(0.3 \%)$ & \\
\hline Combination & $360(61.5 \%)$ & $122(61.9 \%)$ & $238(66.9 \%)$ & \\
\hline Other & $10(1.7 \%)$ & $5(2.5 \%)$ & $5(1.4 \%)$ & \\
\hline Missing & $33(5.6 \%)$ & & & \\
\hline Time Since Treatment & & & & 0.050 \\
\hline$<1$ year & $83(14.2 . \%)$ & $29(19.7 \%)$ & $54(17.9 \%)$ & \\
\hline $1-4$ years & $177(30.2 \%)$ & $68(46.3 \%)$ & $109(36.2 \%)$ & \\
\hline$\geq 5$ years & $188(32.1 \%)$ & $50(34.0 \%)$ & $138(45.8 \%)$ & \\
\hline Missing & $138(23.5 \%)$ & & & \\
\hline & & & & \\
\hline$\frac{\text { Activity Level }}{<150 \text { minutes }}$ & $288(49.2 \%)$ & $99(46.7 \%)$ & $199(53.2 \%)$ & 0.077 \\
\hline$\geq 150$ minutes & $298(50.8 \%)$ & $113(53.5 \%)$ & $175(46.8 \%)$ & \\
\hline Sleep Duration & & & & $<0.001$ \\
\hline$\leq 4$ hours & $40(6.0 \%)$ & $20(9.6 \%)$ & $20(5.4 \%)$ & \\
\hline 5-6 hours & $240(41.0 \%)$ & $107(51.4 \%)$ & $133(35.8 \%)$ & \\
\hline$\geq 7$ hours & $300(51.2 \%)$ & $81(38.9 \%)$ & $219(58.9 \%)$ & \\
\hline Missing & $6(1.0)$ & & & \\
\hline
\end{tabular}




\begin{tabular}{|c|c|c|c|c|}
\hline Cancer Type & & & & 0.002 \\
\hline Cervical & $46(7.8 \%)$ & $25(13.5 \%)$ & $21(6.2 \%)$ & \\
\hline Endometrial & $337(57.6 \%)$ & $123(66.5 \%)$ & $214(63.5 \%)$ & \\
\hline Ovarian & $139(23.7 \%)$ & $37(20.0 \%)$ & $102(30.3 \%)$ & \\
\hline Other & $64(10.9 \%)$ & & & \\
\hline Characteristic & $\mathbf{N}$ & Non-white & White & $p$ \\
\hline Fall recurrence & & & & 0.821 \\
\hline Nonrecurrent & $494(84.3 \%)$ & $176(86.7 \%)$ & $318(86.4 \%)$ & \\
\hline Recurrent & $73(12.5 \%)$ & $27(13.3 \%)$ & $46(12.6 \%)$ & \\
\hline Missing & $19(3.2 \%)$ & & & \\
\hline Fall risk & & & & 0.118 \\
\hline Agree & $167(28.5 \%)$ & $70(34.7 \%)$ & $97(26.4 \%)$ & \\
\hline Neutral & $78(13.3 \%)$ & $25(12.4 \%)$ & $53(14.4 \%)$ & \\
\hline Disagree & $324(55.3 \%)$ & $107(53.0 \%)$ & $217(59.1 \%)$ & \\
\hline Missing & $17(2.9 \%)$ & & & \\
\hline Bodily Pain & & & & $<0.001$ \\
\hline Yes & $176(30.7 \%)$ & $124(58.8 \%)$ & $151(41.0 \%)$ & \\
\hline No & $397(69.3 \%)$ & $87(41.2 \%)$ & $217(59 / 0 \%)$ & \\
\hline Physical Pain & & & & $<0.001$ \\
\hline Yes & $273(47.4 \%)$ & $127(60.8 \%)$ & $273(73.8 \%)$ & \\
\hline No & $303(52.6 \%)$ & $82(39.2 \%)$ & $97(26.2 \%)$ & \\
\hline & & & & \\
\hline Depression & & & & 0.276 \\
\hline Yes & $174(30.1 \%)$ & $69(32.9 \%)$ & $105(28.5 \%)$ & \\
\hline No & $404(69.9 \%)$ & $141(67.1 \%)$ & $263(71.5 \%)$ & \\
\hline Comorbidities & & & & 0.869 \\
\hline 0 & $111(19.3 \%)$ & $38(17.9 \%)$ & $75(20.3 \%)$ & \\
\hline 1 & $158(27.5 \%)$ & $59(27.8 \%)$ & $100(27.1 \%)$ & \\
\hline 2 & $129(22.5 \%)$ & $51(24.1 \%)$ & $80(21.7 \%)$ & \\
\hline 3 & $83(14.5 \%)$ & $28(13.2 \%)$ & $56(15.2 \%)$ & \\
\hline$\geq 4$ & $93(16.2 \%)$ & $36(17.0 \%)$ & $58(15.7 \%)$ & \\
\hline
\end{tabular}

Table 1. Demographic and health behavior characteristics of respondents.

Concerning fall risk and physical activity as potential concerns for cancer survivors, the respondents in this sample who identified as postmenopausal cervical cancer survivors reported a moderate concern about fall risk compared to their premenopausal counterparts $(p=0.048)$. Physical activity levels increased as time since treatment increased $(p=0.003)$ regardless of cancer type. There were no other remarkable associations between fall risk or physical activity for this study's sample population.

Cervical cancer survivors reported sleeping for less than 7 hours per night $(p=0.015)$. In a stratified analysis of the menopausal status and sleep duration, cervical cancer survivors continued to report fewer hours of sleep than endometrial and ovarian cancer survivors. However, no significant differences were detected between the premenopausal and postmenopausal subgroups. Menopausal status is suggested as a potential modifier of the relationship between time since treatment and sleep duration (premenopausal $p=0.066$ ). However, the stratified analysis would benefit from a larger sample size. A relationship between menopausal status, race, and sleep duration was observed, with non-white postmenopausal survivors reporting $\leq 5$ hours per night in comparison to white postmenopausal women $(p<0.001)$.

Sleep duration differed across white and non-white respondents when examined within each of the three cancer type sub-groups (Table 2). Treatment type differed by cancer type $(p<0.001)$, with chemotherapy as the prevalent treatment experienced by ovarian cancer survivors $(86.2 \%$ ) as compared to $28.4 \%$ of endometrial and $38.6 \%$ of cervical cancer survivors (data not shown). The treatment type was not significantly different in its effect as a modifier of the relationship between race and sleep duration 
(Table 2). However, it did appear as if a stronger relationship between race and sleep duration was present among those survivors who experienced chemotherapy $(p<0.001)$, as compared to those that did not report an experience with chemotherapy $(p<0.035)$.

\begin{tabular}{|c|c|c|c|c|c|c|}
\hline & \multicolumn{2}{|c|}{ Cervical } & \multicolumn{2}{|c|}{ Endometrial } & \multicolumn{2}{|c|}{ Ovarian } \\
\hline Sleep Duration & Non-White & White & Non-white & White & Non-white & White \\
\hline$\leq 4$ hours & $4(16.0 \%)$ & $4(19.0 \%)$ & $11(9.1 \%)$ & $12(5.7 \%)$ & $4(11.4 \%)$ & $3(2.9 \%)$ \\
\hline 5-6 hours & $10(40.0 \%)$ & $11(52.4 \%)$ & $63(52.1 \%)$ & $75(35.4 \%)$ & $18(51.4 \%)$ & $30(29.4 \%)$ \\
\hline \multirow[t]{3}{*}{$\geq 7$ hours } & $11(44.0 \%)$ & $6(28.6 \%)$ & $47(38.8 \%)$ & $125(59.0 \%)$ & $13(37.1 \%)$ & $69(67.6 \%)$ \\
\hline & & $\begin{array}{l}p=0.555 \text { for sleep } \\
\text { duration } \mathrm{x} \text { race } \\
\text { among cervical } \\
\text { cancer cases }\end{array}$ & & $\begin{array}{l}p=0.002 \text { for sleep } \\
\text { duration } \mathrm{x} \text { race } \\
\text { among } \\
\text { endometrial } \\
\text { cancer cases }\end{array}$ & & $\begin{array}{l}p=0.003 \\
\text { for sleep } \\
\text { duration } \mathrm{x} \\
\text { race among } \\
\text { ovarian } \\
\text { cancer cases }\end{array}$ \\
\hline & \multicolumn{2}{|c|}{ Chemo } & \multicolumn{2}{|c|}{ No chemo } & & \\
\hline Sleep Duration & Non-white & White & Non-white & White & & \\
\hline$\leq 4$ hours & $10(11.9 \%)$ & $7(4.4 \%)$ & $9(8.3 \%)$ & $12(6.2 \%)$ & & \\
\hline $5-6$ hours & $47(56.0 \%)$ & $51(31.9 \%)$ & $54(50.0 \%)$ & $71(36.6 \%)$ & & \\
\hline \multirow[t]{3}{*}{$\geq 7$ hours } & $27(32.1 \%)$ & $102(63.8 \%)$ & $45(41.7 \%)$ & $111(57.2 \%)$ & & \\
\hline & & $\begin{array}{c}p<0.001 \text { for sleep } \\
\text { duration } \mathrm{x} \text { race } \\
\text { among those who } \\
\text { received } \\
\text { chemotherapy }\end{array}$ & & $\begin{array}{c}p=0.035 \text { for sleep } \\
\text { duration } \mathrm{x} \text { race } \\
\text { among those who } \\
\text { did not receive } \\
\text { chemotherapy }\end{array}$ & & \\
\hline & \multicolumn{2}{|c|}{ Chemo } & \multicolumn{2}{|c|}{ No chemo } & & \\
\hline Sleep Duration & Premenopausal & Postmenopausal & Premenopausal & Postmenopausal & & \\
\hline$\leq 4$ hours & $7(7.1 \%)$ & $10(6.9 \%)$ & $12(10.2 \%)$ & $9(5.0 \%)$ & & \\
\hline 5-6 hours & $40(40.4 \%)$ & $58(40.3 \%)$ & $42(35.6 \%)$ & $81(45.0 \%)$ & & \\
\hline \multirow[t]{2}{*}{$\geq 7$ hours } & $52(52.5 \%)$ & $76(52.8 \%)$ & $64(54.2 \%)$ & $90(50.0 \%)$ & & \\
\hline & & $\begin{array}{c}p=0.999 \text { for } \\
\text { sleep duration } \mathrm{x} \\
\text { menopausal status } \\
\text { among those who } \\
\text { received } \\
\text { chemotherapy }\end{array}$ & & $\begin{array}{c}p=0.107 \text { for } \\
\text { sleep duration } \mathrm{x} \\
\text { menopausal status } \\
\text { among those who } \\
\text { did not receive } \\
\text { chemotherapy }\end{array}$ & & \\
\hline
\end{tabular}

Table 2. Associations between race and menopausal status with sleep duration, stratified by cancer type and treatment type. 


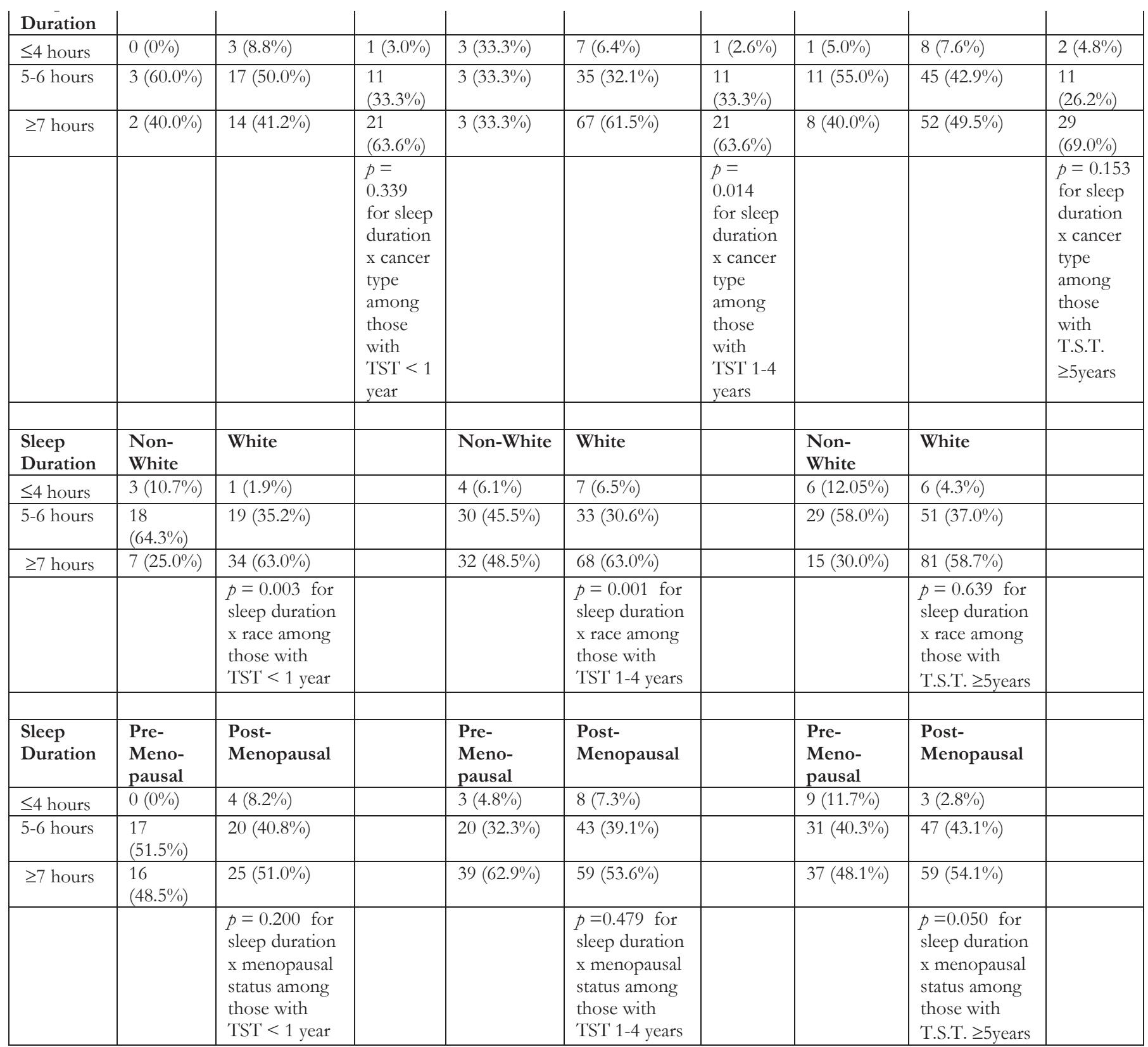

Table 3. Associations between time since last treatment and sleep duration, stratified by cancer type, race, and menopausal status.

Treatment type did not modify the relationship between menopausal status and sleep duration or between time since treatment and sleep duration (data not shown). Time since treatment and sleep duration were examined with cancer type, race, and menopausal status (Table 3). Heterogeneity was suggested among survivors less than five years from their last treatment, with the observation of non-white survivors reporting fewer hours of sleep per night than white survivors $(<1$ year since treatment: $p=0.003,1-4$ years since treatment: $p=0.001)$.

Self-reported depression was analyzed with demographic characteristics, medical history, and health behavior characteristics (data not shown). Depression was not directly related to race, menopausal status, time since treatment, physical activity, or cancer type. Depression was inversely related to sleep duration $(p=0.022)$ and positively related to bodily pain $(p<0.001)$, physical pain $(p<$ $0.001)$, and number of comorbidities $(p<0.001)$.

\section{DISCUSSION}

The findings in this cross-sectional study are consistent with those of Westin et al., who reported a more significant number of sleep disturbances among cervical cancer survivors. ${ }^{28}$ We also observed non-white cancer survivors reporting fewer hours of sleep 
per night than white cancer survivors. This observation is apparent across cancer type with potential modification by menopausal status, treatment type, and time since treatment. A previously published study with a similar focus on racial disparities in sleep used an actigraphy assessment and documented less sleep per night among non-white breast cancer survivors than white survivors. ${ }^{33}$ Future studies that focus specifically on sleep duration and quality, with both subjective (e.g., self-report on Pittsburgh Sleep Quality Index) and objective (e.g., sleep actigraphy) assessments are needed more racially/ethnically diverse groups of cancer survivors.

Health behavior interventions to-date have focused on the increased risk of obesity-related cancer recurrence and the development of type 2 diabetes mellitus among cancer survivors. However, there is evidence that a more nuanced approach is needed to address health behaviors that would support sleep quality and mental health concerns. Several studies cite a myriad of biological, sociological, and environmental theories for racial disparities in sleep behaviors and sleep quality; however, there is limited research on specific cancer survivors' associations. ${ }^{34,35}$ Interventions are needed to examine and address survivors' perceptions of their H.R.Q.O.L. and the risk of depression. ${ }^{24,26,36,37}$ Negative coping styles and self-perceptions, coupled with sleep disturbances, may contribute to long-term and debilitating mental health conditions. As with the assessment of sleep, future studies should focus more narrowly on the dimensions of depression and distress in cancer survivors using instruments such as, but not limited to, the Beck Depression Inventory and National Comprehensive Cancer Network's Distress Thermometer.

In addition to expanding the lens of survivorship care beyond metabolic risk factors to include sleep duration and mental health, research and interventions also need to aggressively focus on accurately measuring and describing the H.R.Q.O.L. disparities in non-white populations and among those of lower socioeconomic status. ${ }^{17,38,39}$ All cancer survivors have the potential to experience post-treatment effects. However, those survivors who live at the intersection of both racial and socioeconomic disparities in sleep duration and mental health will, arguably, have the largest barriers to knowledge and sustainable access to appropriate services. ${ }^{40}$

Despite the statistical significance of the results presented herein, it is crucial to consider this study's limitations. Questionnaires were sent through postal mail to the address listed in the cancer registry database. Email addresses were not collected by the cancer registry and were not available for this study. Lack of familiarity or personal connection with the institution making the request contributed to the low response rate. No financial incentive was offered for completion and return of the questionnaire, which may have impacted the response rate. Despite a response rate of $10 \%$, which is lower than the target response rate for a single mailing, without incentives, of $15-20^{0} 0^{23,41,42}$ we did note that the respondents' demographics are comparable to the demographics of the population identified by the cancer registry. A cross-sectional sample of approximately 600 respondents does limit the magnitude of the impact of the stratified analyses. However, findings from this sample size can provide useful insight toward the specific aims of a future, subsequent study. This study's focus on gynecologic cancer survivors strengthens the literature, which has previously focused on breast cancer survivors. However, it is essential to consider the source population and the geographic and social confounders within Los Angeles County before extrapolating these observations to gynecologic cancer survivors at the state or national level. Given the lower representation of cervical and ovarian cancer cases and the lower representation of non-White cases in the L.A. County cancer registry, it would be prudent to over-sample these sub-groups in future studies.

\section{CONCLUSION}

This study highlights the importance of focusing in on depression and sleep duration in the context of cancer type, treatment type, exercise behaviors, and race to understand better health disparities among cancer survivors that might lead to long-term deficits in mental health and H.R.Q.O.L. Future studies should include an objective clinical assessment of disease burden using the Charlson Comorbidity Index for more recent cancer survivors, in comparison to those who have experienced more time since treatment cessation. This study suggests that disparities are most prevalent among cancer survivors that have more recently completed treatment. Additionally, non-white cancer survivors experience insufficient sleep duration and depression despite participating in physical activity, which has been previously shown to improve white cancer survivors' sleep and depression. Increased attention is needed for cancer survivors in the first year after treatment cessation to identify and mitigate racial and socioeconomic disparities in sleep duration and H.R.Q.O.L.

\section{ACKNOWLEDGEMENTS}

The authors sincerely thank the anonymous survey respondents that took the time to complete the health questionnaire that this analysis was based. We are grateful to Danielle Good-Dawson for consistent administrative support. We would also like to thank the following divisions and programs at Loyola Marymount University to support student research assistants: Frank R. Seaver College of Science and Engineering, the Rains Research Assistant Program, and the Summer Undergraduate Research Program. 


\section{AUTHORS' DISCLOSURES}

The cost of registry access and postal mailings for this study was funded by the Tower Cancer Research Foundation's Community Partner Grant (award period: 1/1/15-12/31/15) and an award granted by the Charitable Division of the QueensCare Foundation (award period: $1 / 1 / 15-12 / 31 / 15$ ). These funding sources did not provide salary support for the authors. Hembrick, Conner, and Tarleton declare that they have no competing conflicts of interest.

\section{REFERENCES}

1. Bluethmann, S. M., Mariotto, A. B., and Rowland, J. H. (2016) Anticipating the "silver tsunami": Prevalence trajectories and comorbidity burden among older cancer survivors in the united states, Cancer Epidemiol Biomarkers Prev 25, 1029-1036. bttps: / / doi.org/10.1158/1055-9965.EPI-16-0133

2. Siegel, R. L., Miller, K. D., and Jemal, A. (2019) Cancer statistics, 2019, CA Cancer J Clin 69, 7-34. bttps:// doi.org/10.3322/caac.21551

3. Loud, J. T., and Murphy, J. (2017) Cancer screening and early detection in the 21(st) century, Semin Oncol Nurs 33, 121 128. https:// doi.org/10.1016/j.soncn.2017.02.002

4. Goldman, M. E. (2017) Life after treatment: Quality-of-life concerns in patients treated for cancer, J Natl Compr Canc Netw 15, 744-747. bttps:// doi.org/10.6004/jnccn.2017.0090

5. Domnick, M., Domnick, M., Wiebelitz, K. R., and Beer, A. M. (2017) Evaluation of the effectiveness of a multimodal complementary medicine program for improving the quality of life of cancer patients during adjuvant radiotherapy and/or chemotherapy or outpatient aftercare, Oncology 93, 83-91. https:// doi.org/10.1159/000468939

6. Lukowski, J., Gil, K. M., Jenison, E., Hopkins, M., and Basen-Engquist, K. (2012) Endometrial cancer survivors' assessment of the benefits of exercise, Gynecol Oncol 124, 426-430. bttps:// doi.org/10.1016/j.ygyno.2011.11.002

7. Yun, Y. H., Kim, Y. A., Lee, M. K., Sim, J. A., Nam, B. H., Kim, S., Lee, E. S., Noh, D. Y., Lim, J. Y., Kim, S., Kim, S. Y., Cho, C. H., Jung, K. H., Chun, M., Lee, S. N., Park, K. H., and Park, S. (2017) A randomized controlled trial of physical activity, dietary habit, and distress management with the leadership and coaching for health (leach) program for disease-free cancer survivors, BMC Cancer 17, 1-12. https:/ / doi.org/10.1186/s12885-017-3290-9

8. Donnelly, C. M., Lowe-Strong, A., Rankin, J. P., Campbell, A., Blaney, J. M., and Gracey, J. H. (2013) A focus group study exploring gynecological cancer survivors' experiences and perceptions of participating in a rct testing the efficacy of a home-based physical activity intervention, Support Care Cancer 21, 1697-1708. bttps:// doi.org/10.1007/s00520-012-1716-0

9. Zhang, X., McClean, D., Ko, E., Morgan, M. A., and Schmitz, K. (2017) Exercise among women with ovarian cancer: A feasibility and pre-/post-test exploratory pilot study, Oncol Nurs Forum 44, 366-374. bttps:// doi.org/10.1188/17.ONF.366-374

10. Cho, D., and Park, C. L. (2018) Barriers to physical activity and healthy diet among breast cancer survivors: A multilevel perspective, Eur J Cancer Care (Engl) 27, 1-8. bttps:/ / doi.org/10.1111/ecc.12772

11. Catt, S., Sheward, J., Sheward, E., and Harder, H. (2018) Cancer survivors' experiences of a community-based cancerspecific exercise programme: Results of an exploratory survey, Support Care Cancer 26, 3209-3216. https:// doi.org/10.1007/s00520-018-4179-0

12. Ray, A. D., Twarozek, A. M., Williams, B. T., Erwin, D. O., Underwood, W., 3rd, and Mahoney, M. C. (2018) Exercise in african american and white colorectal cancer survivors: A mixed methods approach, Rehabil Oncol 36, 188-197. bttps:// doi.org/10.1097/01.REO.0000000000000125

13. Yang, D. D., Hausien, O., Aqeel, M., Klonis, A., Foster, J., Renshaw, D., and Thomas, R. (2017) Physical activity levels and barriers to exercise referral among patients with cancer, Patient Educ Couns 100, 1402-1407. bttps: / doi.org/10.1016/j.pec.2017.01.019

14. Hardcastle, S. J., Maxwell-Smith, C., Kamarova, S., Lamb, S., Millar, L., and Cohen, P. A. (2018) Factors influencing non-participation in an exercise program and attitudes towards physical activity amongst cancer survivors, Support Care Cancer 26, 1289-1295. bttps:// doi.org/10.1007/s00520-017-3952-9

15. Aycinena, A. C., Valdovinos, C., Crew, K. D., Tsai, W. Y., Mata, J. M., Sandoval, R., Hershman, D., and Greenlee, H. (2017) Barriers to recruitment and adherence in a randomized controlled diet and exercise weight loss intervention among minority breast cancer survivors, J Immigr Minor Health 19, 120-129. https:// doi.org/10.1007/s10903-015-0310-1

16. Clifford, B. K., Mizrahi, D., Sandler, C. X., Barry, B. K., Simar, D., Wakefield, C. E., and Goldstein, D. (2018) Barriers and facilitators of exercise experienced by cancer survivors: A mixed methods systematic review, Support Care Cancer 26, 685-700. bttps:/ / doi.org/10.1007/s00520-017-3964-5

17. Stewart, J. L., Besenyi, G. B., Williams, L. B., Burt, V., Anglin, J. C., Ghamande, S. A., and Coughlin, S. S. (2017) Healthy lifestyle intervention for african american uterine cancer survivors: Study protocol, Contemp Clin Trials Commun 8, 11-17. bttps:// doi.org/10.1016/j.conctc.2017.08.011

18. Ross, J. G. C., Escamilla, V., Lee, N. K., Diane Yamada, S., and Lindau, S. T. (2018) Geospatial patterns of access to 
self-care resources for obesity among endometrial cancer survivors in a high poverty urban community, Gynecol Oncol 152, 322-27. bttps:/ / doi.org/10.1016/j.ygyno.2018.12.005

19. Farrokhzadi, L., Dhillon, H. M., Goumas, C., Young, J. M., and Cust, A. E. (2016) Physical activity correlates, barriers, and preferences for women with gynecological cancer, Int J Gynecol Cancer 26, 1530-1537. bttps:/ / doi.org/10.1097/IGC.0000000000000790

20. Bird, M. L., Cheney, M. J., and Williams, A. D. (2016) Accidental fall rates in community-dwelling adults compared to cancer survivors during and post-treatment: A systematic review with meta-analysis, Oncol Nurs Forum 43, E64-E72. https:/ / doi.org/10.1188/16.ONF.E64-E72

21. Campbell, G., Wolfe, R. A., and Klem, M. L. (2018) Risk factors for falls in adult cancer survivors: An integrative review, Rehabil Nurs 43, 201-213. https:// doi.org/

22. Schmitt, A. C., Repka, C. P., Heise, G. D., Challis, J. H., and Smith, J. D. (2017) Comparison of posture and balance in cancer survivors and age-matched controls, Clin Biomech (Bristol, Avon) 50, 1-6. https:// doi.org/10.1016/j.clinbiomech.2017.09.010

23. Lucas, A. R., Focht, B. C., Cohn, D. E., Klatt, M. D., and Buckworth, J. (2018) Recruiting endometrial cancer survivors to studies examining lifestyle behaviors and quality of life: Challenges faced and lessons learned, J Cancer Educ 33, 857-864. https:// doi.org/10.1007/s13187-017-1187-6

24. Dahl, L., Wittrup, I., Vaeggemose, U., Petersen, L. K., and Blaakaer, J. (2013) Life after gynecologic cancer--a review of patients quality of life, needs, and preferences in regard to follow-up, Int J Gynecol Cancer 23, 227-234. bttps:// doi.org/10.1097/IGC.0b013e31827f37b0

25. Carpenter, K. M., Fowler, J. M., Maxwell, G. L., and Andersen, B. L. (2010) Direct and buffering effects of social support among gynecologic cancer survivors, Ann Behav Med 39, 79-90. https:/ / doi.org/ 10.1007/s12160-010-9160-1

26. Yi, J. C., and Syrjala, K. L. (2017) Anxiety and depression in cancer survivors, Med Clin North Am 101, 1099-1113. https://doi.org/10.1016/j.mcna.2017.06.005

27. Osann, K., Hsieh, S., Nelson, E. L., Monk, B. J., Chase, D., Cella, D., and Wenzel, L. (2014) Factors associated with poor quality of life among cervical cancer survivors: Implications for clinical care and clinical trials, Gynecol Oncol 135, 266-272. https://doi.org/10.1016/j.ygyno.2014.08.036

28. Westin, S. N., Sun, C. C., Tung, C. S., Lacour, R. A., Meyer, L. A., Urbauer, D. L., Frumovitz, M. M., Lu, K. H., and Bodurka, D. C. (2016) Survivors of gynecologic malignancies: Impact of treatment on health and well-being, J Cancer Surviv 10, 261-270. https:// doi.org/10.1007/s11764-015-0472-9

29. Armbruster, S. D., Song, J., Gatus, L., Lu, K. H., and Basen-Engquist, K. M. (2018) Endometrial cancer survivors' sleep patterns before and after a physical activity intervention: A retrospective cohort analysis, Gynecol Oncol 149, 133139. https:/ / doi.org/10.1016/j.ygyno.2018.01.028

30. Zhou, E. S., Partridge, A. H., Syrjala, K. L., Michaud, A. L., and Recklitis, C. J. (2017) Evaluation and treatment of insomnia in adult cancer survivorship programs, J Cancer Surviv 11, 74-79. https:// doi.org/10.1007/s11764-016-0564-1

31. Watson, N. F., Badr, M. S., Belenky, G., Bliwise, D. L., Buxton, O. M., Buysse, D., Dinges, D. F., Gangwisch, J., Grandner, M. A., Kushida, C., Malhotra, R. K., Martin, J. L., Patel, S. R., Quan, S. F., and Tasali, E. (2015) Recommended amount of sleep for a healthy adult: A joint consensus statement of the american academy of sleep medicine and sleep research society, Sleep 38, 843-844. https:// doi.org/10.5665/ sleep.4716

32. Sanders, K. M., Stuart, A. L., Scott, D., Kotowicz, M. A., and Nicholson, G. C. (2015) Validity of 12-month falls recall in community-dwelling older women participating in a clinical trial, Int J Endocrinol 2015, 1-6. https://doi.org/10.1155/2015/210527

33. Budhrani, P. H., Lengacher, C. A., Kip, K. E., Tofthagen, C., and Jim, H. (2014) Minority breast cancer survivors: The association between race/ethnicity, objective sleep disturbances, and physical and psychological symptoms, Nurs Res Pract 2014, 1-11. https:/ / doi.org/10.1155/2014/858403

34. Grandner, M. A. (2017) Sleep, health, and society, Sleep Med Clin 12, 1-22. https://doi.org/10.1016/j.jsmc.2016.10.012

35. Egan, K. J., Knutson, K. L., Pereira, A. C., and von Schantz, M. (2017) The role of race and ethnicity in sleep, circadian rhythms and cardiovascular health, Sleep Med Rev 33, 70-78. https:/ / doi.org/10.1016/j.smrv.2016.05.004

36. Dobrzycka, B., Terlikowski, R., Kulesza-Bronczyk, B., Niklinski, J., and Terlikowsk, S. J. (2017) Quality of life in long-term survivors of early stage endometrial cancer, Ann Agric Environ Med 24, 513-516. bttps:/ / doi.org/ 10.5604/12321966.1232759

37. Mamguem Kamga, A., Dumas, A., Joly, F., Billa, O., Simon, J., Poillot, M. L., Darut-Jouve, A., Coutant, C., Fumoleau, P., Arveux, P., and Dabakuyo-Yonli, T. S. (2018) Long-term gynecological cancer survivors in cote d'or: Health-related quality of life and living conditions, Oncologist 24, e490-e500. https:/ / doi.org/10.1634/ theoncologist.20180347

38. Khan, H. M., Gabbidon, K., Saxena, A., Abdool-Ghany, F., Dodge, J. M., 3rd, and Lenzmeier, T. (2016) Disparities in cervical cancer characteristics and survival between white hispanics and white non-hispanic women, $J W o m e n s$ Health (Larchmt) 25, 1052-1058. https:/ / doi.org/10.1089/jwh.2015.5585 
39. Yoo, W., Kim, S., Huh, W. K., Dilley, S., Coughlin, S. S., Partridge, E. E., Chung, Y., Dicks, V., Lee, J. K., and Bae, S. (2017) Recent trends in racial and regional disparities in cervical cancer incidence and mortality in united states, PLoS One 12,1-13. https:// doi.org/10.1371/journal.pone.0172548

40. Martin, J. Y., Schiff, M. A., Weiss, N. S., and Urban, R. R. (2017) Racial disparities in the utilization of preventive health services among older women with early-stage endometrial cancer enrolled in medicare, Cancer Med 6, 21532163. https:/ / doi.org/10.1002/ cam4.1141

41. Toomey, S. L., Elliott, M. N., Zaslavsky, A. M., Quinn, J., Klein, D. J., Wagner, S., Thomson, C., Wu, M., Onorato, S., and Schuster, M. A. (2019) Improving response rates and representation of hard-to-reach groups in family experience surveys, Acad Pediatr 19, 446-453. https:/ / doi.org/10.1016/j.acap.2018.07.007

42. Williams, M. S., Snyder, D. C., Sloane, R., Levens, J., Flynn, K. E., Dombeck, C. B., Demark-Wahnefried, W., and Weinfurt, K. P. (2013) A comparison of cancer survivors from the promis study selecting telephone versus online questionnaires, Psychooncology 22, 2632-2635. https://doi.org/10.1002/pon.3330

\section{ABOUT STUDENT AUTHORS}

Ma'at Hembrick and Makala Conner graduated from Loyola Marymount University in May 2019 and each received a Bachelor of Science degree in Health and Human Sciences. Ma'at is working as an Office Manager at a dietitian's private practice named, Elizabeth Baron Cole \& Associates. Makala works at Eco Works, a non-profit organization that informs Detroit Public School students about their environment and promotes sustainable living projects for students and faculty members.

\section{PRESS SUMMARY}

Among a surveyed group of gynecological survivors from the Cancer Registry, sleep quality was measured as a determinant of quality of health. Sleep quality among these survivors was also analyzed in relation to race, postmenopausal status, cancer type, and depression. In conclusion, this study found noteworthy relationships between the aforementioned variables and sleep quality, and further proposes exploring racial disparity in sleep quality among a larger, multi-ethnic group of gynecological survivors.

\section{APPENDIX}

\begin{tabular}{|c|c|}
\hline Original Variable & Data Analysis Format for Categorical \\
\hline Age & Age Mean $66.54 \pm 2.6$ \\
\hline Reported in years (continuous) & 49-64 yrs old \\
\hline & 65-69 yrs old \\
\hline & $70+$ yrs old \\
\hline Ethnicity & Ethnicity \\
\hline American Indian & Non-white \\
\hline Asian/ Asian Pacific & Non-white \\
\hline Black & Non-white \\
\hline Hispanic & Non-white \\
\hline Other & Non-white \\
\hline White & White \\
\hline Education level & Education level \\
\hline$<$ High School & $\leq$ High School \\
\hline Some high school & $\leq$ High School \\
\hline High school graduate & $\leq$ High School \\
\hline Some college & Attended college \\
\hline 2 -year college graduate & Graduated from either a 2 or 4 year program \\
\hline 4-year college graduate & Graduated from either a 2 or 4 year program \\
\hline $\begin{array}{l}\text { Menopausal status } \\
\text { Are you currently in menopause? }\end{array}$ & Menopausal status \\
\hline No & Premenopausal \\
\hline Yes & Postmenopausal \\
\hline
\end{tabular}




\begin{tabular}{|c|c|}
\hline Treatment Type & Treatment Type \\
\hline Surgery & No chemo \\
\hline Radiation & No chemo \\
\hline Chemotherapy & Chemo \\
\hline Blood Transfusion & No chemo \\
\hline Other & Other \\
\hline Time Since Treatment & Time Since Treatment \\
\hline What was the date of your last treatment? & $<1$ year \\
\hline \multirow[t]{2}{*}{ (reported by month and year) } & $1-4$ years \\
\hline & $\geq 5$ years \\
\hline Activity Level & Activity Level \\
\hline \multirow{2}{*}{$\begin{array}{l}\text { Minutes spent exercising per day (continuous) multiplied by } \\
\text { number of days spent exercising per week (continuous). }\end{array}$} & $<150$ minutes \\
\hline & $\geq 150$ minutes \\
\hline Sleep Duration & Sleep Duration \\
\hline 4 hours & 4 hours \\
\hline 5 hours & 5 hours \\
\hline$\geq 7$ hours & $\geq 7$ hours \\
\hline Original Variable & Data Analysis Format for Categorical \\
\hline Cancer Type & Cancer Type \\
\hline What type of cancer were you diagnosed with? & Cervical \\
\hline & Endometrial \\
\hline & Ovarian \\
\hline & Other \\
\hline $\begin{array}{l}\text { Fall recurrence } \\
\text { How many times have you fallen within the past } 12 \text { months? } \\
\text { (continuous) }\end{array}$ & Fall recurrence \\
\hline $0-1$ & Nonrecurrent \\
\hline$\geq 2$ & Recurrent \\
\hline $\begin{array}{c}\text { Fall risk } \\
\text { Please respond to this statement: "I am at risk for falls." }\end{array}$ & Fall risk \\
\hline Strongly Agree & Agree \\
\hline Somewhat Agree & Agree \\
\hline Neutral & Neutral \\
\hline Somewhat Disagree & Disagree \\
\hline Strongly Disagree & Disagree \\
\hline $\begin{array}{l}\text { Bodily Pain } \\
\text { How much "bodily pain" have you generally had during the } \\
\text { past } 4 \text { weeks, while doing normal daily activities? }\end{array}$ & Bodily Pain \\
\hline Severe & Yes \\
\hline Quite a Bit & Yes \\
\hline Moderate & Yes \\
\hline
\end{tabular}




\begin{tabular}{|c|c|}
\hline Very Little & No \\
\hline None & No \\
\hline $\begin{array}{c}\text { Physical Pain } \\
\text { Do you have a bone or joint problem in your leg that limits } \\
\text { your physical activity? }\end{array}$ & Physical Pain \\
\hline Yes & Yes \\
\hline No & No \\
\hline $\begin{array}{l}\text { Depression } \\
\text { In general, how much depression have you experienced in the } \\
\text { past } 4 \text { weeks? }\end{array}$ & Depression \\
\hline Severe & Yes \\
\hline Quite a Bit & Yes \\
\hline Moderate & Yes \\
\hline Very Little & No \\
\hline None & No \\
\hline Comorbidities & Comorbidities \\
\hline \multirow{4}{*}{$\begin{array}{l}\text { Has a doctor ever told you that you have/had: anemia, } \\
\text { asthma, auto-immune disorder, bladder disease, breast cysts, } \\
\text { chronic bronchitis, chronic fatigue, ulcer, chronic liver } \\
\text { disease, emphysema, fibromyalgia, gall stones, hepatitis, } \\
\text { hyperthyroidism, heart disease, kidney disease, osteoarthritis, } \\
\text { osteogenesis imperfecta, osteopenia/osteoporosis, rectal } \\
\text { polyps, rheumatoid arthritis, stroke, type I diabetes and type } \\
\text { II diabetes }\end{array}$} & 0 \\
\hline & 1 \\
\hline & 2 \\
\hline & 3 \\
\hline $\begin{array}{l}\text { Each condition counted to generate a categorical variable } \\
\text { corresponding to the sum of conditions. }\end{array}$ & $\geq 4$ \\
\hline
\end{tabular}

